\title{
The Stages of CS: Clinical and Translational Update
}

\author{
David A. Baran ${ }^{1} \cdot$ Ashleigh Long ${ }^{2}$ - Jacob C. Jentzer ${ }^{3}$ \\ Accepted: 4 September 2020 / Published online: 14 November 2020 \\ (C) Springer Science+Business Media, LLC, part of Springer Nature 2020
}

\begin{abstract}
Purpose of Review With improvements in cardiovascular care, and routine percutaneous coronary intervention for ST elevation myocardial infarction, more patients are surviving following acute coronary syndromes. However, a minority of patients develop cardiogenic shock which results in approximately 50\% 30-day mortality. There are various ways to classify cardiogenic shock, and much has been written about this topic in recent years. This review will examine recent developments and put them in context.

Recent Findings The large randomized trials of cardiogenic shock treatments such as the IABP-SHOCK II trial used a clinical definition of shock including hypotension (systolic blood pressure of $90 \mathrm{mmHg}$ or less, or requirement of vasopressors to maintain such a blood pressure), as well as hypoperfusion. However, while this defines a minimum standard to define cardiogenic shock, it does not distinguish between a patient on a single vasoconstrictor and one who is on multiple high dose infusions or one on extracorporeal membrane oxygenation. The Society for Cardiac Angiography and Intervention recently published an expert consensus statement defining stages of cardiogenic shock, from at risk to beginning, classic, deteriorating, and extremis cardiogenic shock stages. The simple framework has been validated rapidly in multiple populations including the intensive care unit, a postmyocardial infarction population, an out of hospital cardiac arrest population, and most recently in a multicenter shock collaborative, Summary Classification is fundamental to understanding a disease state, and crafting solutions to improve outcomes. The last 20 years has witnessed an explosion of percutaneous mechanical circulatory support devices of increasing sophistication and capability, and yet there has been little progress in improving outcomes of cardiogenic shock. Hopefully, the next 20 years will see massive advances in understanding of the complexities of the various stages of cardiogenic shock. With such knowledge, it is likely that targeted treatments will be developed and the mortality of this disease will finally plummet.
\end{abstract}

Keywords Cardiogenic shock $\cdot$ Mortality $\cdot$ Classification $\cdot$ Mechanical circulatory support

\section{Introduction}

Cardiogenic shock (CS) is defined as a severe impairment of myocardial performance that results in diminished cardiac

This article is part of the Topical Collection on Cardiogenic Shock: Progress in Mechanical Circulatory Support

David A. Baran

docbaran@gmail.com

1 Sentara Heart Hospital, Eastern Virginia Medical School, 600 Gresham Drive, Norfolk, VA 23507, USA

2 Eastern Virginia Medical School, Norfolk, VA, USA

3 Mayo Clinic, Rochester, MI, USA output, end-organ hypoperfusion, and tissue hypoxia $[1 \bullet \bullet]$. Despite the many advances in cardiovascular care over the last 20 years, the survival of CS patients has not changed substantially, and remains at about $50 \%$ at 30 days following diagnosis. The majority of CS patients are encountered following acute myocardial infarction (AMI), and the value of urgent revascularization in CS was examined in the prospective, randomized Should We Emergently Revascularize Occluded Coronaries for CS (SHOCK) trial [2••]. At 30 days, survival was not statistically significantly different but all-cause mortality was lower for urgently revascularized patients at 6 months. This trial occurred in the era where the only percutaneous circulatory support device was the intra-aortic balloon pump.

The last decade has seen the introduction of mechanical circulatory support (MCS) devices which provide much higher flow than the venerable balloon pump with augmentation of cardiac output up to 4-5 L per minute achievable in some cases, 
yet none has been shown to improve survival compared to medical therapy with or without a balloon pump. The uniform lack of benefit may be due to the heterogeneity of populations of patients studied in these trials [3॰]. The fundamental issue is that the definition of CS is sufficiently vague that patients at many levels of severity may be combined together in clinical trials. This review will examine this issue in detail and review recent developments.

\section{Killip-Kimball Classification}

In 1967, as coronary care units were becoming popular, Killip and Kimball published a classification of myocardial infarction patients that has endured for more than 50 years [4•]. Killip Class I patients are those without heart failure signs. Class II includes patients with rales, an S3 gallop, and elevation of jugular venous pressure. Class III is assigned for patients with frank pulmonary edema and class IV is for patients with CS (defined as systolic blood pressure less than 90 accompanied by signs of hypoperfusion).

\section{SHOCK Trial Definition}

The SHOCK trial defined CS using both clinical and hemodynamic criteria in patients with CS due to AMI (AMI-CS) [2••]. The clinical criteria specified a systolic blood pressure less than $90 \mathrm{mmHg}$ for at least $30 \mathrm{~min}$ or the requirement of supportive measures such as inotropes to maintain a blood pressure of $90 \mathrm{mmHg}$ as well as signs of hypoperfusion including cool, clammy skin, or reduced urine output (less than $30 \mathrm{cc} / \mathrm{h}$ ). The hemodynamic criteria were a cardiac index of $2.2 \mathrm{~L} / \mathrm{min} / \mathrm{m}^{2}$ or less with a pulmonary capillary wedge pressure of at least $15 \mathrm{mmHg}$ (excluding hypovolemic shock). If a patient had an anterior infarction and chest $\mathrm{x}$-ray evidence of pulmonary vascular congestion, then a pulmonary artery catheter was not required to document the hemodynamics.

\section{IAB SHOCK II Trial Definition}

Thiele and colleagues examined the role of the IABP in patients with AMI-CS, showing no difference in survival [5••]. In this trial, CS was defined using the same blood pressure criteria as the SHOCK trial (systolic blood pressure less than $90 \mathrm{mmHg}$ for $30 \mathrm{~min}$ or more, or need of vasopressors to maintain a systolic blood pressure of at least $90 \mathrm{mmHg}$ ), along with clinical pulmonary congestion and clinical signs of hypoperfusion (such as a lactate higher than $2 \mathrm{mmol} / \mathrm{l}$ ). Hemodynamic criteria were not required, reflecting the relatively low use of pulmonary artery catheters in the population. However, there was no gradation of shock severity so a patient on 5 maximum-dose inotrope/vasoconstrictor therapies and a ventilator following a cardiac arrest could be enrolled alongside a hypotensive patient with an inferior infarct and clinical hypoperfusion. This definition was also utilized with the CULPRIT-Shock trial of percutaneous coronary intervention in acute coronary syndrome patients $[6 \bullet \bullet]$.

\section{Alternative Frameworks for Shock}

\section{Mechanistic “Disease-Modifying” Model}

Despite advances in MCS devices, mortality rates of CS caused by AMI have remained at approximately $50 \%$ since the 1990s [5••, 7••]. Lawler and Mehra sought to address the broader systemic impacts of reduced cardiac output in CS through their Mechanistic "Disease-Modifying" Model [8•]. Using the rationale that morbidity and mortality from CS stem directly from complications associated with tissue hypoperfusion, the authors suggested that certain patients in fulminant CS appeared more prone to specific complications following an acute reduction in cardiac output, even when improved hemodynamics were observed from implementation of MCS. It was proposed that specific clinical "phenotypes" could be assigned to CS patients, which represented the evolution of the patient's initial physiologic response to tissue malperfusion into specific and classifiable clinical and pathological pathways. Described as the "mechanistic drivers of shock," the distinct patient phenotypes included the onset of systemic inflammatory response syndrome (SIRS), metabolic derangements, coagulopathies, and development of systemic infection, among others. By better characterizing each patient's "tissue response" to decreased perfusion and the subsequent evolution of specific clinical disease pathways, authors reasoned that earlier and more specific interventions could be employed to improve CS mortality rates. Further, underlying genetic predispositions could potentially be determined, and new drug pathways might be identified with coordinated research efforts in the future. Though potentially impactful, the limitations of this model include the need to identify more biomarkers specific to each clinical phenotype, and how those biomarkers might identify those patients most likely to respond to mechanical intervention. Implicit in this construct is the fundamental understanding that CS begins with hemodynamic compromise that triggers progressive metabolic derangements leading to a self-perpetuating "cardiometabolic" shock phenotype causing a further downward spiral [9॰]. Insofar as most patients dying from CS ultimately succumb to multi-organ failure rather than refractory shock per se, optimizing hemodynamics after the onset of cardiometabolic shock may not be adequate to avert death.

\section{Optimizing MCS Interventions: Timing and Patient Selection}

In patients with AMI-CS, earlier revascularization led to increased rates of survival in the pivotal SHOCK trial $[2 \cdot \bullet]$. 
More recently, The Detroit CS Initiative and later National CS Initiative, a multicenter single arm study group, demonstrated that in AMICS patients, early implementation of MCS prior to revascularization combined with invasive hemodynamic monitoring demonstrated better survival rates than historical controls [10]. However, this was not a randomized trial and conclusions are not definitive. Despite these important studies, a lack of appropriately powered, randomized control trials have prevented consensus in many aspects of AMI-CS management $[11,12 \bullet]$. Previously, many AMI-CS studies involving implementation of MCS did not differentiate between hemodynamic shock and cardiometabolic shock (and in some cases enriched the population in the latter), potentially biasing these studies toward the null and precluding us from drawing conclusions about the effects of MCS on outcomes for ideal MCS candidates with pure hemodynamic shock. Insofar as the severity of hemodynamic compromise should ideally be matched to the degree of support provided by an MCS device, it should not be surprising that the "all-or-none" approach studied in these trials has failed to yield a clear survival benefit.

\section{Mortality Risk Stratification in CS}

Over the years, several authors have used established and novel prognostic markers in CS to develop mortality riskstratification tools specific to this population $[13 \bullet \bullet, 14 \cdot \bullet$, 15•]. These risk scores have generally included demographics, comorbidities, vital signs, and laboratory data to identify CS patients with a higher or lower risk of dying. Unfortunately, most of the variables used to calculate in these risk scores are non-modifiable and reflect the severity of metabolic derangements rather than hemodynamic derangements per se. Therefore, although these risk scores can identify high-risk patients who may do poorly with standard therapies, they cannot necessarily distinguish which patients have a greater degree of hemodynamic compromise that may require more advanced MCS devices. Indeed, these risk scores might paradoxically identify patients who have progressed to cardiometabolic shock and will do poorly with or without MCS, and it remains uncertain how to integrate these risk scores into clinical practice.

\section{How Can We Grade Shock Severity?}

Numerous inter-related factors contribute to an overall assessment of shock severity, including clinical assessments, vital signs, invasive hemodynamics, echocardiographic findings, and laboratory parameters, as well as the usage and dose of supportive therapies $[14 \bullet \bullet, 15 \bullet$. While each of these parameters individually has been associated with increased mortality (presumably reflecting higher shock severity) in patients with $\mathrm{CS}$, few if any studies have integrated multiple parameters to create a comprehensive assessment of shock severity $[1 \bullet \bullet]$. For instance, while greater vasopressor dose requirements are associated with a higher risk of mortality, to interpret such findings in clinical practice requires an understanding of the hemodynamic goals that these drugs are titrated to as well as the achieved hemodynamic parameters. Conversely, worse hemodynamic parameters are associated with a higher risk of mortality, yet the degree of pharmacological and mechanical support needed to achieve these hemodynamic parameters must be taken into account. Clearly, there was a need for a flexible and widely applicable grading system for shock severity that could take into account the heterogeneous data available for each patient to provide a comprehensive assessment of shock severity for use in clinical decision-making.

\section{Development of the SCAI Shock Classification}

In 2017, a group of cardiologists were lamenting the lack of a common "lingua franca" of shock. We had all received patients who were described as "in shock" who were either relatively stable needing only minor medical therapy adjustments or who were completely moribund with refractory shock and organ failure, and there was not a convenient way for the teams to effectively communicate. Moreover, the group was convinced that this lack of granular detail in the definition of shock had contributed to the stalled progress in the field.

The Society for Cardiovascular Angiography and Intervention agreed to sponsor an Expert Consensus Statement on this topic, and a group was assembled including representation from interventional cardiology, advanced heart failure/transplant, critical care medicine, cardiac nursing, emergency medicine, and review from cardiothoracic surgery and multiple professional societies. The final statement was published in early 2019 [16••].

\section{CS According to the SCAI Shock Classification}

The expert consensus statement defined 5 stages of CS, from A to E (as illustrated in the Fig. 1). For each stage, there are physical examination findings, biochemical markers, and hemodynamic parameters which can be identified by the clinician. The intent is that the schema can be employed across the spectrum of care, utilizing the available information at hand. Therefore, a prehospital care provider (who does not have access to invasive hemodynamics or laboratory data) is equally able to use this system as the clinician in the cardiac catheterization laboratory, or the bedside critical care nurse. Criteria for the SCAI Stages are summarized in the Table 1.

Stage A represents patients who not in shock, but are At risk. This includes patients with acute coronary syndromes as well as those with acute decompensations of chronic heart 


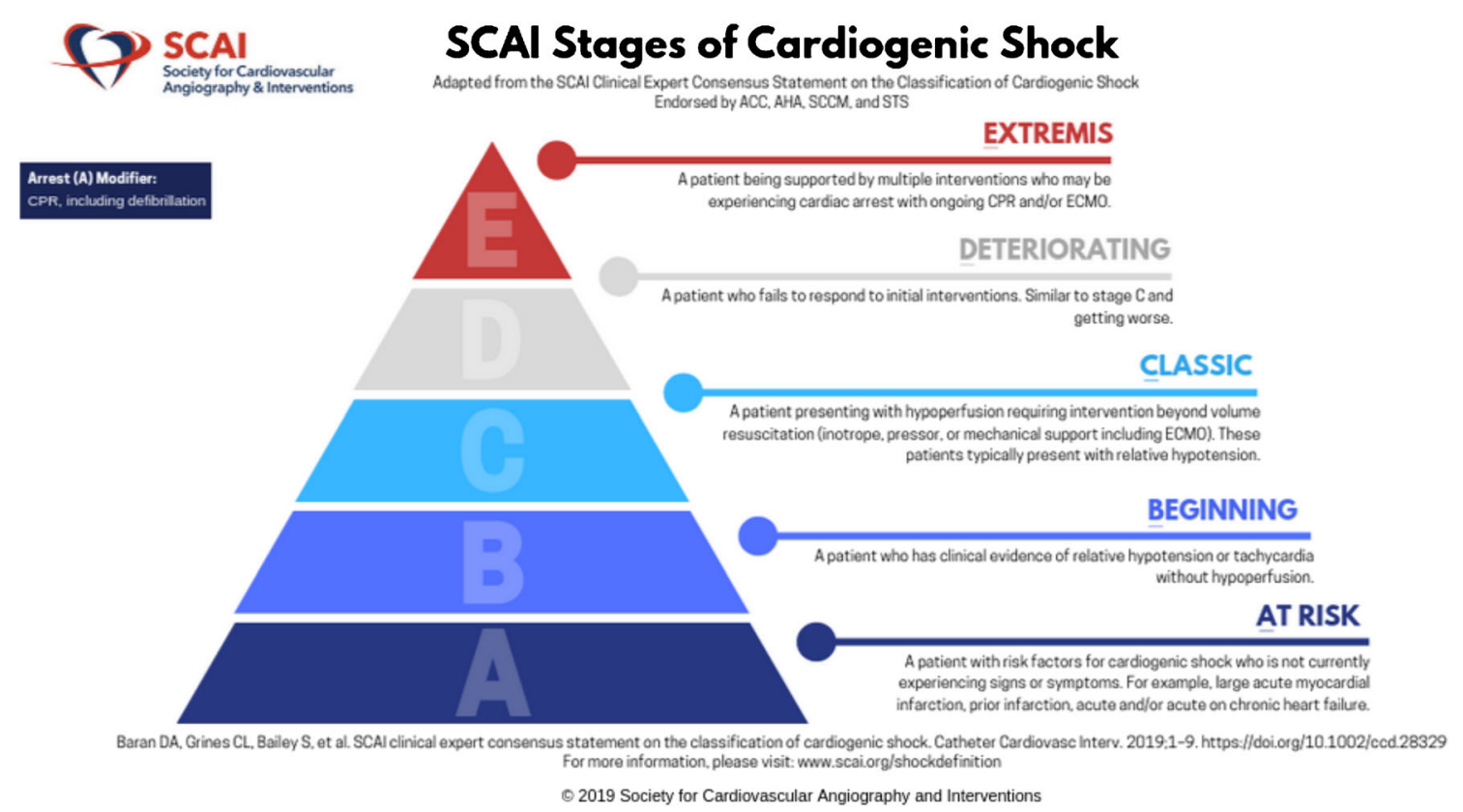

Fig. 1 Graphical Illustration of the SCAI Shock Pyramid. Downloaded from http://www.scai.org/image.axd?id=02d6b9f9-d279-4620-9b14$9 \mathrm{ffb} 1 \mathrm{e} 388414 \& \mathrm{t}=637056965436500000$. Used with permission (but remains copyright of SCAI)

failure. Stage B describes patients with Beginning or early shock, manifest by hypotension and / or tachycardia, but with maintained perfusion status. Such patients have been referred to as "pre-shock" by some authors $[8 \cdot, 17,18]$. Stage C is Classic CS with hypoperfusion in addition to findings from stage B, recognizing that most but not all Stage $C$ patients will demonstrate absolute or relative hypotension. Stage D is for patients who are Deteriorating despite initial efforts to treat them. Stage E reflects patients in Extremis who typically are experiencing cardiovascular collapse, and are requiring heroics to support life. The system has a single "modifier" which is $\mathbf{A}$, for arrest. Any defibrillation or cardiopulmonary resuscitation grants the patient the " $\mathrm{A}$ " modifier, based on the consensus that patients with arrest are on a fundamentally different trajectory than those who may be quite ill but do not suffer a cardiac arrest, with additional harmful pathophysiologic pathways affecting outcomes. It is not known whether a single brief shock without cardiopulmonary resuscitation portends the same prognosis as an arrest with more prolonged course.

The classification is intended for repeated assessments and integration into future trial design so that patients may be accurately identified at the beginning of their illness, rather than retrospectively classifying them which is subject to bias since the outcome is often clear at later time periods. During development, there was vigorous debate about whether to limit the classification to only AMI-CS patients, or whether strict laboratory or hemodynamic criteria would need to be met prior to adjudicating stages. In the end, we decided that regardless of etiology (heart failure or acute ischemia), the SCAI classification could be applied effectively. Moreover, it was critically important that the system was accessible across the care spectrum and therefore rigid rules gave way to the suggested characteristics of each group.

\section{Validation of the SCAI Shock Classification}

The intent of the authors was for others to examine the predictive accuracy of the SCAI classification and ascertain whether its application would prognosticate patient outcomes. Jentzer and colleagues from the Mayo Clinic first validated the SCAI Shock Classification in a group of more than 10,000 intensive care unit patients [19••]. The authors mapped the definitions into discrete data that was examined in their intensive care unit. The hospital mortality varied quite significantly from $3 \%$ in Stage A to $67 \%$ in stage E, and shock severity as measured using the SCAI stages remained a strong predictor of mortality even after adjusting for standard clinical risk factors. Importantly, the SCAI classification determined within 1 to $24 \mathrm{~h}$ of intensive care unit admission predicted outcome in AMI-CS patients and those with CS due to heart failure. The group went on to show that admission SCAI stage predicts long-term survival for patients who are successfully discharged from the hospital [20]. The "A" modifier was also examined in this population, and as predicted by the expert consensus committee, the presence of cardiac arrest fundamentally alters the prognosis in a negative fashion (particularly for patients with non-shockable arrest rhythms) [21••].

A group from Germany led by Schrage had similar findings [22•]. The group reported on 1007 consecutive patients with CS (Stages B through E) or large myocardial infarction (Stage A) seen between 2009 and 2017, using a different paradigm to 
Table 1 Descriptors of shock stages: physical exam, biochemical markers and hemodynamics. From: [16]

\begin{tabular}{|c|c|c|c|c|}
\hline Stage & Description & $\begin{array}{l}\text { Physical exam/bedside } \\
\text { findings }\end{array}$ & Biochemical markers & Hemodynamics \\
\hline At risk & $\begin{array}{l}\text { A Patient who is not currently experiencing } \\
\text { signs or symptoms of CS, but is at risk } \\
\text { for its development. These patients may } \\
\text { include those with large acute myocardial } \\
\text { infarction or prior infarction acute and/or } \\
\text { acute on chronic heart failure symptoms }\end{array}$ & $\begin{array}{l}\text { Normal JVP } \\
\text { Lung sounds clear } \\
\text { Warm and well perfused } \\
\text { - Strong distal pulses } \\
\text { - Normal mentation }\end{array}$ & $\begin{array}{l}\text { Normal labs } \\
\text { • Normal renal function } \\
\text { - Normal lactate }\end{array}$ & $\begin{array}{l}\text { Normotensive (SBP } \geq 100 \\
\quad \text { or normal for pt) } \\
\text { If hemodynamics done } \\
\text { - Cardiac index } \geq 2.5 \\
\text { - } \text { CVP }<10 \\
\text { - PA sat } \geq 65 \%\end{array}$ \\
\hline B Beginning CS & $\begin{array}{l}\text { A patient who has clinical evidence of relative } \\
\text { hypotension or tachycardia without } \\
\text { hypoperfusion }\end{array}$ & $\begin{array}{l}\text { Elevated JVP } \\
\text { Rales in lung fields } \\
\text { Warm and well perfused } \\
\text { - Strong distal pulses } \\
\text { - Normal mentation }\end{array}$ & $\begin{array}{l}\text { Normal lactate } \\
\text { Minimal renal function } \\
\text { impairment } \\
\text { Elevated BNP }\end{array}$ & $\begin{array}{l}\mathrm{SBP}<90 \text { OR MAP }<60 \\
\quad \mathrm{OR}>30 \mathrm{mmHg} \text { drop } \\
\quad \text { from baseline } \\
\text { Pulse } \geq 100 \\
\text { - Cardiac index } \geq 2.2 \\
\text { - PA sat } \geq 65 \%\end{array}$ \\
\hline C Classic CS & $\begin{array}{l}\text { A patient that manifests with hypoperfusion } \\
\text { that requires intervention (inotrope, pressor } \\
\text { or mechanical support, including ECMO) } \\
\text { beyond volume resuscitation to restore } \\
\text { perfusion. These patients typically present } \\
\text { with relative hypotension }\end{array}$ & $\begin{array}{l}\text { May include Any of: } \\
\text { Looks unwell } \\
\text { Panicked } \\
\text { Ashen, mottled, dusky } \\
\text { Volume overload } \\
\text { Extensive rales } \\
\text { Killip class } 3 \text { or } 4 \\
\text { BIPAP or mechanical } \\
\text { ventilation } \\
\text { Cold, clammy } \\
\text { Acute alteration in mental } \\
\text { status } \\
\text { Urine output }<30 \mathrm{~mL} / \mathrm{h}\end{array}$ & $\begin{array}{l}\text { May include Any of } \\
\text { Lactate } \geq 2 \\
\text { Creatinine doubling } \\
\text { OR }>50 \% \text { drop in GFR } \\
\text { Increased LFTs } \\
\text { Elevated BNP }\end{array}$ & $\begin{array}{l}\text { May include of: } \\
\mathrm{SBP}<90 \text { OR MAP }<60 \\
\text { OR }>30 \mathrm{mmHg} \text { drop from } \\
\text { baseline } A N D \text { drugs/device } \\
\text { used to maintain } \mathrm{BP} \text { above } \\
\text { these targets } \\
\text { Hemodynamics } \\
\text { - Cardiac index }<2.2 \\
\text { - } \mathrm{PCWP}>15 \\
\text { - RAP } / \mathrm{PCWP} \geq 0.8 \\
\text { - PAPI }<1.85 \\
\text { - Cardiac power output } \leq 0.6\end{array}$ \\
\hline D Deteriorating & $\begin{array}{l}\text { A patient that is similar to category } \mathrm{C} \text { but } \\
\text { are getting worse. They have failure to } \\
\text { respond to initial interventions }\end{array}$ & Any of stage $\mathrm{C}$ & $\begin{array}{l}\text { Any of Stage C AND } \\
\text { Deteriorating }\end{array}$ & $\begin{array}{l}\text { Any of Stage C AND } \\
\text { Requiring multiple pressors } \\
\text { OR addition of mechanical } \\
\text { circulatory support devices } \\
\text { to maintain perfusion }\end{array}$ \\
\hline E Extremis & $\begin{array}{l}\text { A patient that is experiencing cardiac arrest } \\
\text { with ongoing CPR and/ or ECMO, being } \\
\text { supported by multiple interventions }\end{array}$ & $\begin{array}{l}\text { Near pulselessness } \\
\text { Cardiac collapse } \\
\text { Mechanical ventilation } \\
\text { Defibrillator used }\end{array}$ & $\begin{array}{l}\text { "Trying to die" } \\
\text { CPR (A-modifier) } \\
\mathrm{pH} \leq 7.2 \\
\text { Lactate } \geq 5\end{array}$ & $\begin{array}{l}\text { No SBP without resuscitation } \\
\text { PEA or refractory VT/VF } \\
\text { Hypotension despite maximal } \\
\text { support }\end{array}$ \\
\hline
\end{tabular}

define the SCAI classification. The 30-day survival was $96.4 \%$ for those in SCAI Stage A, $46.1 \%$ in Stage C, and only $22.6 \%$ in stage E. Similar results were reported by Hanson et al. using 300 patients with CS (classified as Stages C through E using a new paradigm) from the National Cardiogenic Shock Initiative, who examined SCAI stage both on presentation and at $24 \mathrm{~h}$, showing incrementally higher rates of death and organ failure as SCAI stage increased (particularly for 24-h SCAI stage) [23•].

Pareek and colleagues published a series of 393 resuscitated out of hospital cardiac arrest patients in South London who underwent emergency coronary angiography for a presumed cardiac etiology [24•]. Patients were retrospectively assigned to a SCAI shock grade (again using a novel definition) with blinding to the outcome of the hospitalization. The SCAI shock classification was easily applied and resulted in highly significant discrimination for outcomes at 30 days and 1-year post-presentation. In addition, the group found that the mode of death was quite different across SCAI class, with the majority of SCAI A and B patients dying due to neurologic dysfunction and increasing numbers of patients succumbing to multi-organ failure or cardiac dysfunction as initial SCAI stage worsens.

Thayer and colleagues report the experience of the multicenter cardiogenic shock working group (8 academic centers which collaborate to share data on refractory cardiogenic shock) [25••]. They reported 1414 patients, of which 1116 had invasive hemodynamic data. The group defined the SCAI stages in retrospect and mapped SCAI stage B to patients on no vasoactive drugs nor MCS devices (rare). Stage $\mathrm{C}$ was considered to be one drug or one device but not both. Concurrent use of one intravenous drug and one MCS device 
was considered to identify SCAI stage D. SCAI Stage E was assigned when either the patient was on 2 or more vasoactive drugs or 2 kinds of MCS devices were employed (i.e., transition from one device to a $2 \mathrm{nd}$, or 2 simultaneous devices). The authors reported that in hospital mortality tracked with the SCAI stages, though they did not provide long-term mortality data. As noted in the accompanying editorial, there are number of ways to retrospectively map populations to the SCAI stages [26].

While all of these studies have used distinct definitions of the SCAI stages, the message is clear and consistent—shock severity grading using the SCAI shock stages is feasible in research using definitions that could be applied in clinical practice, and provides robust risk-stratification of CS patients.

\section{Future Applications of Shock Staging}

It is abundantly clear that more powerful MCS pumps are not the answer to improving the survival of CS patients who have established multi-organ failure and anoxic brain injury. No trial has shown convincing improvements in outcomes with any of the current percutaneous support options, and ECMO is under study but does not seem likely to be the universal solution to this problem either given the roughly $50 \%$ survival observed in most studies of ECMO for CS. Most of us in the field feel that patient selection is one of the most important aspects to improving outcomes. By selecting patients according to a validated staging system, it is hoped that we may discover what approaches may be best for each stage. Just as no one would reach for ECMO in a stage $\mathrm{B}$, it is unclear whether there are any ideal approaches for stage E patients who are in many cases too late to salvage. Earlier and more systematic application of escalating hemodynamic support tailored to shock severity during the hemodynamic phase of CS would seem to be an ideal strategy.

The original hope of the expert consensus group was that future prospective randomized trials in CS would incorporate mandatory stratification of patients by initial SCAI stage. This way, poor patient selection would not lead to the failure of a device to show a benefit, and on the contrary would lead to a better understanding of the patient groups who could derive maximum benefit from a particular therapy. Further refinements of the SCAI classification may be able to account for the crucial distinction between hemodynamic and cardiometabolic shock, enabling more accurate conclusions to be drawn about the impact of MCS timing on outcomes.

In addition, it is hoped that the SCAI stage becomes a common way for first responders to describe patients. In particular, with the emergency medical system now very comfortable with immediate diagnosis of STEMI, one could envision every STEMI being classified from A to E which would help hospitals receiving these patients. The recent American
Heart Association Statement on CS suggested that "shock centers" might be established to triage patients with severe shock preferentially to such hospitals but did not have any easy way for pre-hospital providers to identify such patients $[1 \bullet \bullet]$. The SCAI classification potentially represents a powerful tool in the formation of such a new process of care for shock patients, allowing optimal triage to hospitals providing the level of support needed by each patient based on SCAI stage. Furthermore, the SCAI classification could potentially be implemented automatically using our increasingly sophisticated electronic health record systems, in order to facilitate early recognition and intervention.

\section{Conclusions}

While AMI care has progressed immensely over the last 20 years, with multiple trials guiding practice, the field of CS (which often results from AMI) has not advanced as swiftly. We described the prior schema to classify CS patients, and presented the evidence supporting the new SCAI shock staging classification. What is abundantly clear is that new approaches to CS are necessary to understand this complex and deadly syndrome, beyond simply treating its initial manifestations such as low cardiac output. Until we have insight into the fundamental pathophysiologic mechanisms that are activated following a myocardial insult that triggers CS, we are doomed to repeat history by performing an ongoing series of negative trials with larger and more capable MCS pumps. By staging CS, at least we may gather whether some subgroups are able to benefit from early interventions and which ones may prove to be beyond help.

\section{Compliance with Ethical Standards}

Conflict of Interest Dr. Baran has consulted with Getinge, Livanova, Abiomed, MC3, Novartis, and Pfizer. None of these are relevant to the current manuscript. None of the other authors have relevant conflicts.

Human and Animal Rights and Informed Consent This article does not contain any studies with human or animal subjects performed by any of the authors.

\section{References}

Papers of particular interest, published recently, have been highlighted as:

- Of importance

•. Of major importance

1.• van Diepen S, Katz JN, Albert NM, Henry TD, Jacobs AK, Kapur NK, et al. Contemporary management of cardiogenic Shock: a scientific statement from the American Heart Association. Circulation. 
2017;136(16):e232-e68. https://doi.org/10.1161/cir. 0000000000000525 Important scientific statement from AHA laying groundwork for Shock Centers and the importance of hub and spoke approaches to cardiogenic shock.

2.• Hochman JS, Sleeper LA, Webb JG, Sanborn TA, White HD, Talley JD, et al. Early revascularization in acute myocardial infarction complicated by cardiogenic shock. SHOCK Investigators. Should We Emergently Revascularize Occluded Coronaries for Cardiogenic Shock. N Engl J Med. 1999;341(9):625-34. https:// doi.org/10.1056/nejm199908263410901 Seminal study of revascularization in cardiogenic shock which is the last trial to demonstrate improvements in outcome. Note that the primary endpoint was not met, but a secondary was met at 6 months.

3. Thiele H, Jobs A, Ouweneel DM, Henriques JPS, Seyfarth M, Desch S, et al. Percutaneous short-term active mechanical support devices in cardiogenic shock: a systematic review and collaborative meta-analysis of randomized trials. Eur Heart J. 2017;38(47):352331. https://doi.org/10.1093/eurheartj/ehx363 Meta-analysis of the existing randomized trials of percutaneous MCS devices. None improves mortality.

4. Killip T 3rd, Kimball JT. Treatment of myocardial infarction in a coronary care unit. A two year experience with 250 patients. Am J Cardiol. 1967;20(4):457-64. https://doi.org/10.1016/00029149(67)90023-9 Original and still occasionally used classification of post myocardial infarction patients with shock.

5.• Thiele H, Zeymer U, Neumann FJ, Ferenc M, Olbrich HG, Hausleiter $\mathrm{J}$, et al. Intra-aortic balloon counterpulsation in acute myocardial infarction complicated by cardiogenic shock (IABPSHOCK II): final 12 month results of a randomised, open-label trial. Lancet (London, England). 2013;382(9905):1638-45. https://doi.org/10.1016/s0140-6736(13)61783-3 12 month results of the IABP versus medical therapy in post-MI shock.

6.• Thiele H, Akin I, Sandri M, Fuernau G, de Waha S, Meyer-Saraei $\mathrm{R}$, et al. PCI strategies in patients with acute myocardial infarction and cardiogenic shock. N Engl J Med. 2017;377(25):2419-32. https://doi.org/10.1056/NEJMoa1710261 Results of the CULPRIT-Shock trial which showed that PCI of the culprit vessel resulted in lower mortality than multivessel PCI.

7.• Thiele H, Zeymer U, Neumann FJ, Ferenc M, Olbrich HG, Hausleiter J, et al. Intraaortic balloon support for myocardial infarction with cardiogenic shock. N Engl J Med. 2012;367(14):128796. https://doi.org/10.1056/NEJMoa1208410 Landmark trial of IABP versus medical therapy in post-MI shock.

8. Lawler PR, Mehra MR. Advancing from a "hemodynamic model" to a "mechanistic disease-modifying model" of cardiogenic shock. J Heart Lung Transplant : the official publication of the International Society for Heart Transplantation. 2018;37(11):1285-8. https://doi. org/10.1016/j.healun.2018.07.009 Interesting perspective piece regarding a phenotypic classification of shock.

9. Esposito M, Kapur N. Acute mechanical circulatory support for cardiogenic shock: the ?Door to support? Time [version 1; peer review: 3 approved]. 2017;6(737). https://doi.org/10.12688/ f1000research.11150.1. Perspective paper discussing the rationale for primary rapid ventricular unloading as opposed simply minimizing door to balloon time.

10. Basir MB, Kapur NK, Patel K, Salam MA, Schreiber T, Kaki A, et al. Improved outcomes associated with the use of shock protocols: updates from the National Cardiogenic Shock Initiative. Catheter Cardiovasc Interv : official journal of the Society for Cardiac Angiography \& Interventions. 2019;93(7):1173-83. https://doi.org/10.1002/ccd.28307.

11. Basir MB. Beyond the coronary arteries, should we be shifting our focus to mechanical circulatory support in patients with acute myocardial infarction and cardiogenic shock? Cardiovas Revasc Med : including molecular interventions. 2020;21:849-50. https://doi.org/ 10.1016/j.carrev.2020.04.039.

12. Kapur NK, Davila CD. Timing, timing, timing: the emerging concept of the 'door to support' time for cardiogenic shock. Eur Heart J. 2017;38(47):3532-4. https://doi.org/10.1093/eurheartj/ehx406 Perspective regarding the idea that earlier mechanical support may improve outcomes even more than rapid coronary revascularization by percutaneous intervention. (similar to Esposito and Kapur above).

13.• Harjola VP, Lassus J, Sionis A, Kober L, Tarvasmaki T, Spinar J, et al. Clinical picture and risk prediction of short-term mortality in cardiogenic shock. Eur J Heart Fail. 2015;17(5):501-9. https://doi. org/10.1002/ejhf.260 This paper discusses the CARDSHOCK risk score in cardiogenic shock along with validation.

14.• Poss J, Koster J, Fuernau G, Eitel I, de Waha S, Ouarrak T, et al. Risk stratification for patients in cardiogenic shock after acute myocardial infarction. J Am Coll Cardiol. 2017;69(15):1913-20. https://doi.org/10.1016/j.jacc.2017.02.027 The IAB SHOCK-II risk score is described along with validation.

15. Sleeper LA, Reynolds HR, White HD, Webb JG, Dzavík V, Hochman JS. A severity scoring system for risk assessment of patients with cardiogenic shock: a report from the SHOCK Trial and Registry. Am Heart J. 2010;160(3):443-50. https://doi.org/10. 1016/j.ahj.2010.06.024 The SHOCK trial risk score is described. It did not achieve widespread use.

16.• Baran DA, Grines CL, Bailey S, Burkhoff D, Hall SA, Henry TD, et al. SCAI clinical expert consensus statement on the classification of cardiogenic shock: This document was endorsed by the American College of Cardiology (ACC), the American Heart Association (AHA), the Society of Critical Care Medicine (SCCM), and the Society of Thoracic Surgeons (STS) in April 2019. Catheter Cardiovasc Interv : official journal of the Society for Cardiac Angiography \& Interventions. 2019;94(1):29-37. https://doi.org/10.1002/ccd.28329 SCAI Shock Classification document giving guidelines for assessing the new SCAI Shock stage.

17. O'Rourke MF, Chang VP. The "pre-shock" stage of massive myocardial infarction. Results of treatment with arterial counterpulsation. Med J Aust. 1974;2(23):841-5.

18. Schäfer A, Burkhoff D, Bauersachs J. Haemodynamic simulation and the effect of early left ventricular unloading in pre-shock acute coronary syndrome. ESC heart failure. 2019;6(3):457-63. https:// doi.org/10.1002/ehf2.12417.

19.• Jentzer JC, van Diepen S, Barsness GW, Henry TD, Menon V, Rihal CS, et al. Cardiogenic shock classification to predict mortality in the cardiac intensive care unit. J Am Coll Cardiol. 2019;74(17): 2117-28. https://doi.org/10.1016/j.jacc.2019.07.077 First validation of the SCAI Shock Stage classification with more than 10,000 intensive care unit patients in a retrospective study.

20. Jentzer JC, Baran DA, van Diepen S, Barsness GW, Henry TD, Naidu SS, et al. Admission Society for Cardiovascular Angiography and Intervention shock stage stratifies postdischarge mortality risk in cardiac intensive care unit patients. Am Heart J. 2020;219:37-46. https://doi.org/10.1016/j.ahj.2019.10. 012 .

21.• Jentzer JC, Henry TD, Barsness GW, Menon V, Baran DA, Van Diepen S. Influence of cardiac arrest and SCAI shock stage on cardiac intensive care unit mortality. Catheter Cardiovasc Interv: official journal of the Society for Cardiac Angiography \& Interventions. 2020. https://doi.org/10.1002/ccd.28854 Further analysis of a 10,000 patient intensive care unit population examining the potent effect of a cardiac arrest (however brief).

22. Schrage B, Dabboura S, Yan I, Hilal R, Neumann JT, Sörensen NA, et al. Application of the SCAI classification in a cohort of patients with cardiogenic shock. Catheter Cardiovasc Interv : official journal of the Society for Cardiac Angiography \& 
Interventions. 2020. https://doi.org/10.1002/ccd.28707 Second retrospective validation of the SCAI Shock Classification in 1000 patients at a single center.

23. Hanson ID, Tagami T, Mando R, Kara Balla A, Dixon SR, Timmis S, Almany S, Naidu SS, Baran D, Lemor A, Gorgis S, O'Neill W, Basir MB. National Cardiogenic Shock Investigators. SCAI shock classification in acute myocardial infarction: Insights from the National Cardiogenic Shock Initiative. Catheter Cardiovasc Interv. 2020. https://doi.org/10.1002/ccd.29139. Validation of the SCAI Shock classification in a population of AMI cardiogenic shock patients from the National Cardiogenic Shock Initiative group.

24. Pareek N, Dworakowski R, Webb I, Barash J, Emezu G, Melikian N, Hill J, Shah A, MacCarthy P, Byrne J. SCAI cardiogenic shock classification after out of hospital cardiac arrest and association with outcome. Catheter Cardiovasc Interv. 2020. https://doi.org/10. 1002/ccd.28984. Validation of the SCAI Shock classification in a population of out of hospital cardiac arrest patients.

25.• Thayer KL, Kapur NK. Invasive hemodynamic assessment and classification of in-hospital mortality risk among patients with cardiogenic shock. Circ Heart Fail. 2020;13(9):e007099. Retrospective validation of the SCAI Shock classification in the multicenter cardiogenic shock working group.

26. Jentzer JC. Understanding Cardiogenic Shock Severity and Mortality Risk Assessment. Circ Heart Fail. 2020;13(9):e007568. https://doi.org/10.1161/CIRCHEARTFAILURE.120.007568.

Publisher's Note Springer Nature remains neutral with regard to jurisdictional claims in published maps and institutional affiliations. 